\title{
EFEKTIFITAS LEAFLET TERHADAP PENGETAHUAN DAN MENGATUR POLA MAKAN LANSIA PENDERITA HIPERTENSI DI PUSKESMAS SERASAN KABUPATEN NATUNA
}

\section{LEAFLET EFFECTIVENESS OF KNOWLEDGE AND SETTING THE DIET ELDERLY PATIENTS WITH HYPERTENSION IN HEALTH DISTRICT SERASAN NATUNA}

\author{
Nurvi Susanti, Qodariah, Yessi Harnani, Zulmeliza Rasyid
}

\author{
Program Studi Promosi Kesehatan dan Ilmu Perilaku \\ Ilmu Kesehatan Masyarakat STIKes Hang Tuah Pekanbaru \\ Email: Shabrina2424@gmaile.com
}

\begin{abstract}
Hypertension is a disease that is incurable but manageable. Good knowledge about hypertension is one right way to prevent and tackle the problem of hypertension. One way to cope with hypertension is to provide information to the public about how to treat hypertension with leafleat. Recapitulation reports obtained from the Natuna District Health Office in 2014 that consists of 12 districts can be seen the most number of hypertension is highest in district Serasan as many as 753 people and the elderly 46 people. The purpose of this study to determine the effectiveness of the leaflet to the knowledge and diet of elderly patients with hypertension in Natunare regency Serasan district health centers in 2015.

The research method is quantitative with quasi experiment. This study was conducted on 12 March 2015 in the Natuna district health centers serasan. Population in this study were all hypertension patients with a total sample of 46 people with sampling by total sampling, the use of computerized data processing and analysis of univariate and bivariate by T test.

Bivariate analysis results are known there is a difference between knowledge before and after given leaflets with value $p=0,000<0,05$, besides there are also differences between respondents diet before and after the given leafleats with the value $p=0,038<0,05$. The conclusion that the leaflet is effective against knowledge and eating habits elderly patients with hypertension.

Serasan district health centers are expected to further improve the Natuna field health promotion services by providing ongoing counseling on a scheduled basis and at least 1 time in a month and multiply media such as posters or leaflet about hypertension as an effort to decrease the incidence of hypertension, especially in the region Natuna regency Serasan district health center.
\end{abstract}

Keywords $\quad$ : Effectiveness, Leaflets, Science Diet and Hypertension

\section{PENDAHULUAN}

Peningkatan Usia Harapan Hidup (UHH) akan menambah jumlah lanjut usia (lansia) yang akan berdampak pada pergeseran pola penyakit di masyarakat dari penyakit infeksi ke penyakit degenerasi. Prevalensi penyakit menular mengalami penurunan, sedangkan penyakit tidak menular cenderung mengalami peningkatan. Penyakit tidak menular (PTM) dapat digolongkan menjadi satu kelompok utama dengan faktor risiko yang sama (common underlying risk faktor) seperti kardiovaskuler, stroke, diabetes mellitus, penyakit paru obstruktif kronik, dan kanker tertentu. Faktor risiko tersebut salah satunya adalah hipertensi (Haryono \& Ningsih, 2013).
Hipertensi atau yang lebih dikenal dengan nama penyakit darah tinggi adalah suatu keadaan di mana terjadi peningkatan tekanan darah di atas ambang batas normal yaitu $120 / 80 \mathrm{mmHg}$. Batas tekanan darah yang masih dianggap normal adalah kurang dari 130/85 mmHg. Bila tekanan darah sudah lebih dari 140/90 mmHg dinyatakan hipertensi (batasan tersebut untuk orang dewasa di atas 18 tahun). Penyakit ini disebut sebagai the silent killer karena penyakit mematikan ini sering sekali tidak menunjukkan gejala atau tersembunyi. Di Belanda lebih dari satu juta orang menderita tekanan darah tinggi tetapi yang mengherankan ialah lebih dari separuhnya tidak mengetahui bahwa mereka 
adalah penderita tekanan darah tinggi (Bustan, 2009).

Menurut World Health Organitation (WHO) tahun 2010, penyakit tekanan darah tinggi atau hipertensi telah membunuh 9,4 juta warga dunia setiap tahunnya. WHO memperkirakan jumlah penderita hipertensi akan terus meningkat seiring dengan jumlah penduduk yang membesar. (Bustan, 2009) Menurut hasil Survei Kesehatan Rumah Tangga (SKRT), kejadian hipertensi di Indonesia mengalami peningkatan setiap tahunnya, dari data tahun 2010 tercatat prevalensi hipertensi sebesar 8,3\%, pada tahun 2011 prevalensi penderita hipertensi mencapai $21 \%$. Selain itu dari hasil estimasi SKRT meramalkan kasus penyakit hipertensi tahun 2015 mencapai $37 \%$ dan tahun 2025 mencapai $42 \%$ (SKRT, 2011).

Menurut Riskesdas tahun 2013, kepulauan Riau merupakan daerah yang paling tinggi jumlah penderita hipertensi. Penyakit hipertensi menempati urutan pertama penyakit terbesar. Penyakit ini mengalami peningkatan dari tahun 2011 tercatat sebanyak 1887, tahun 2012 tercatat 1901 dan tahun 2013 meningkat menjadi 1992 kasus.

Salah satu cara untuk menanggulangi masalah hipertensi adalah dengan memberikan informasi kepada masyarakat tentang cara mengatasi hipertensi. Untuk memberikan informasi tersebut diperlukan beberapa media salah satunya adalah leafleat. Leaflet adalah produk dokumentasi dan komunikasi yang menyediakan pengenalan dan gambaran mengenai sebuah organisasi atau kegiatan. Sebuah leaflet bisa digunakan untuk mempromosikan LSM/ organisasi berbasis masyarakat dengan kegiatannya, mempublikasikan layanan atau kegiatan, dan berkomunikasi dengan pesan, pesan yang spesifik berisi laporansingkat dan informasi yang jelas untuk menyediakan gambaran yang jelas dan sederhana ketimbang deskripsi yang mendetail (Hidayat, 2009).

Menurut penelitian Subarjah (2011), diperoleh hasil sebanyak $67 \%$ leaflet efektif dalam mempengaruhi perilaku seseorang. Penelitian Setiana (2006), diperoleh hasil 70\% keefektivitasan leaflet dipengaruhi oleh pesan gambar yang disampaikan didalam leaflet. Efektifitas merupakan sesuatu yang memiliki pengaruh atau akibat yang ditimbulkan, manjur, membawa hasil dan merupakan keberhasilan dari suatu usaha atau tindakan (Adisusilo, 2010).

Menurut hasil penelitian Urbayan (2012) bahwa penyuluhan dengan menggunakan media leaflet mempengaruhi perilaku masyarakat yang mengalami hipertensi. Selain itu hal ini didukung penelitian Jayanti (2011), bahwa terdapat pengaruh antara penyuluhan dengan menggunakan leaflet terhadap perubahan pola makan lansia penderita Hipertensi.

Leaflet merupakan selembaran kertas yang berisikan tentang informasi khusus. Pada isi leaflet tersedia berbagai informasi yang dibutuhkan dan didukung oleh gambar dengan tujuan pembaca dapat memahami langsung isi dari leaflet. Leaflet merupakan salah satu media yang efektif dalam mempengaruhi perilaku seseorang (Hidayat, 2009). Akan tetapi dari hasil survey awal yang dilakukan peneliti diperoleh informasi dari Puskesmas Serasan, bahwa sebelumnya pernah dilakukan penyuluhan tentang hipertensi dengan menggunakan media poster. Akan tetapi jumlah hipertensi masih cukup tinggi di Puskesmas tersebut, dimana hasil rekapitulasi laporan penyakit tidak menular khusus penyakit hipertensi yang diperoleh dari Dinas Kesehatan Kabupaten Natuna tahun 2014 yang terdiri dari 12 Kecamatan dapat diketahui jumlah penyakit hipertensi yang paling tertinggi terdapat di Kecamatan Serasan yaitu sebanyak 753 orang dan pada lasnsia 46 orang, sedangkan pada tahun 2013 kejadian hipertensi tercatat 602 orang dan pada lansia tercatat 38 orang, kondisi ini kasus hipertensi mengalami peningkatan setiap tahunnya. Berdasarkan survei awal yang dilakukan terhadap 10 orang yang berkunjung ke Puskesmas Serasan diperoleh hasil sebanyak 8 orang memiliki pengetahuan kurang tentang hipertensi yang meliputi pengertian, penyebab, cara mencegah penyakit hipertensi dan lain sebagainya.sehingga kondisi ini tidak menutup kemungkinan penyakit hipertensi di Serasan dapat terus meningkat jika tidak segera diatasi. 


\section{METODOLOGI PENELITIAN}

Jenis penelitian ini adalah analitik kuantitatif secara Quasi Experiment dengan rancangan One Group Pretest-Posttest Design, yang dilaksanakan pada tanggal 12 Maret sampai dengan 10 Mei tahun 2015, diwilayah kerja puskesmas Serasan kabupaten Natuna. Sampel dalam penelitian ini adalah seluruh lansia yang mengalami hipertensi dan berada di Kelurahan Serasan Kabupaten Natuna, yang berjumlah 46 orang. Teknik pengambilan sampel menggunakan teknik total sampling.

Pengambilan data dilakukan dengan data primer yaitu melakukan wawancara dengan menggunakan kuesioner. Data sekunder meliputi data tentang gambaran umum wilayah penelitian. Analisis data menggunakan analisis univariat di mana masing-masing variabel dikategorikan sesuai dengan hasil ukur dan dilakukan persentase dalam bentuk tabel distribusi frekuensi dan analisis bivariat untuk mengetahui ada tidaknya hubungan antara variabel independen dengan variabel dependen dapat digunakan dengan T-Independen dan uji $T$ Dependen.

\section{HASIL DAN PEMBAHASAN}

\section{Analisis Univariat}

Analisis univariat menunjukkan bahwa distribusi frekuensi responden berdasarkan variabel independen dan variabel dependen diketahui bahwa dari 46 responden distribusi frekuensi responden berdasarkan karakteristik dari 46 responden distribusi frekuensi responden berdasarkan pengetahuan dan pola makan lansia penderita hipertensi dari 46 responden pada penelitian ini didapatkan responden dalam variabel pengetahuan sebelum diberikan penyuluhan mayoritas berpengetahuan rendah yaitu sebanyak 32 orang $(69,6 \%)$ dan sesudah

Tabel 1

Distribusi Frekuensi Responden Berdasarkan Variabel Independen dan Variabel Dependen di Wilayah Kerja Puskesmas Kambesko Kabupaten Indragiri Hulu Tahun 2015

\begin{tabular}{cccc}
\hline No & Pengetahuan sebelum & F & Persentase (\%) \\
\hline 1. & Tinggi & 14 & 30,4 \\
2. & Rendah & 32 & 69,6 \\
\hline & Pengetahuan sesudah & F & Persentase (\%) \\
\hline 1. & Tinggi & 37 & 80,4 \\
2. & Rendah & 9 & 19,6 \\
\hline
\end{tabular}

diberikan penyuluhan pengetahuan responden tinggi sebanyak 37 orang $(80,4 \%)$. Sedangkan untuk variabel pola makan sebelum diberikan penyuluhan mayoritas memiliki pola makan kurang sebanyak 36 orang $(78,3 \%)$ dan sesudah diberikan penyuluhan pola makan responden baik sebanyak 23 orang $(50,0 \%)$.

\section{Analisis Bivariat}

Hasil uji $\mathrm{T}$ dependen diketahui bahwa nilai rata-rata pengetahuan sebelum diberikan leaflet adalah 4,93 dengan standar deviasi adalah 1,57. Sedangkan nilai rata-rata pengetahuan setelah diberikan leaflet adalah 6,59 dengan standar deviasi adalah 1,67. Hasil uji statistik diperoleh $p$ value $0,00<0,05$ yang berarti ada perbedaan antara pengetahuan sebelum dan pengetahuan sesudah diberikan leaflet.

Hasil uji T-Independen menunjukkan dari 46 responden didapatkan selisih rata-rata 1.66 dengan SD 1,57. Hasil uji statistik diperoleh $\mathrm{p}$ value $=0,00$ atau $\mathrm{p}<0,05$.artinya terdapat perbedaan yang bermakna antara pengetahuan sebelum dan sesudah diberikan leaflet

Hasil uji $\mathrm{T}$ dependen diketahui bahwa nilai rata-rata pola makan sebelum diberikan leaflet adalah 4,72 dengan standar devisiasi $=1,377$. Rata-rata pola makan sesudah diberikan leaflet adalah 5,54 dengan standar devisiasi=1,810.

Hasil uji statistik didapat nilai $\mathrm{p}=0,038$ maka dapat disimpulkan ada perbedaan yang signifikan antara pola makan sebelum dan sesudah diberikan leaflet.

Hasil uji T-Independen menunjukkan dari 46 responden didapatkan selisih rata-rata 0,82 dengan SD 1,377. Hasil uji statistik diperoleh $\mathrm{p}$ value $=0,38$ atau $\mathrm{p}<0$ 0,05.artinya terdapat perbedaan yang bermakna antara pengetahuan sebelum dan sesudah diberikan leaflet 


\begin{tabular}{|c|c|c|c|}
\hline & Pola makan sebelum & $\mathbf{F}$ & Persentase (\%) \\
\hline 1. & Baik & 10 & 21,7 \\
\hline \multirow[t]{2}{*}{2.} & Kurang & 36 & 78,3 \\
\hline & Pola makan sesudah & $\mathbf{F}$ & Persentase (\%) \\
\hline 1. & Baik & 23 & 50,0 \\
\hline \multirow[t]{3}{*}{2.} & Kurang & 23 & 50,0 \\
\hline & Total & 46 & 100 \\
\hline & Efektivitas Leaflet & $\mathbf{F}$ & Persentase (\%) \\
\hline 1. & Tidak Efektif & 15 & 32,6 \\
\hline \multirow[t]{2}{*}{2.} & Efektif & 31 & 67,4 \\
\hline & Total & 46 & 100 \\
\hline
\end{tabular}

Tabel 2

Perbedaan Rata-rata Pengetahuan dan Pola Makan Sebelum dan Sesudah Diberi Leaflet pada Penderita Hipertensi di Puskesmas Serasan Kabupaten Natuna tahun 2015

\begin{tabular}{ccccccc}
\cline { 2 - 6 } No & Variabel & Mean & SD & SE & P Value & n \\
\hline 1. & Pengetahuan & & & & & \\
& Sebelum & 4,93 & 1,56 & 0,23 & 0,00 & 46 \\
& Sesudah & 6,59 & 1,668 & 0,246 & & \\
\hline 2. & Pola Makan & & & & & 46 \\
& Sebelum & 4,72 & 1,37 & 0,203 & 0,038 & \\
& Sesudah & 5,54 & 1,810 & 0,267 & & \\
\hline
\end{tabular}

Tabel 3

Efektifitas Leaflet Terhadap Pengetahuan dan Pola Makan pada Penderita Hipertensi di Puskesmas Serasan Kabupaten Natuna Tahun 2015

\begin{tabular}{|c|c|c|c|c|c|c|c|}
\hline \multirow{2}{*}{ No } & \multirow[t]{2}{*}{ Variabel } & \multicolumn{2}{|c|}{ Nilai Rata-rata } & \multirow{2}{*}{\multicolumn{3}{|c|}{ Selisih Rata- SD }} & \multirow[t]{2}{*}{ SE $\quad$ P Value } \\
\hline & & Sebelum & Sesudah & & & & \\
\hline 1. & Pengetahuan & 4,93 & 6,59 & 1,66 & & 1,57 & $0,231 \quad 0,00$ \\
\hline 2. & Pola Makan & 4,72 & 5,54 & 0,82 & & 1,377 & 0,203 \\
\hline
\end{tabular}

\section{a. Efektifitas Leaflet Terhadap Pengetahuan Lansia Penderita Hipertesi di Puskesmas Serasan Kabupaten Natuna \\ Berdasarkan hasil penelitian diketahui bahwa} $\mathrm{p}^{\text {value }}=0,000<0,05$. Hal ini menunjukan bahwa Ho ditolak yang artinya leaflet efektif dalam mempengaruhi pengetahuan lansia hipertensi dengan kata lain penyuluhan dengan menggunakan leaflet mempengaruhi pengetahuan pada lansia yang mengalami hipertensi di Puskesmas Serasan Kabupaten Natuna tahun 2015.

Penelitian ini didukung oleh teori Pujiriyanto (2009). Leaflet berfungsi sebagai alat sederhana pengingat pesan dimana pembaca dapat belajar secara mandiri informasi yang terdapat didalamnya termasuk detil (misalnya statistik) yang tidak mungkin bisa disampaikan lisan. Leaflet yang digunakan dalam sosialisasi pelayanan haruslah leaflet yang komunikatif dimana dapat mempermudah masyarakat dalam memahami isi pesan sehingga sosialisasi pelayanan kesehatan khususnya penanggulangan atau penatalaksanaan hipertensi dapat tercapai dengan baik.

Hasil penelitian ini didukung oleh penelitian Urbayan (2012), yang bertujuan untuk mengetahui efektivitas penyuluhan dengan menggunakan media leaflet terhadap pengetahuan masyarakat untuk penanganan hipertensi di Puskesmas Sakar Ayu Dumai, dimana hasil penelitian diperoleh bahwa penyuluhan dengan menggunakan media leaflet mempengaruhi perilaku masyarakat yang mengalami hipertensi.

Berdasarkan asumsi penelitian diketahui terdapat perbedaan antara pengetahuan responden yang mendapatkan informasi dan yang tidak mendapatkan informasi melalui media leaflet tentang hipertensi bahwa leaflet efektif dalam mempengaruhi pengetahuan responden tentang hipertensi. Hal ini disebabkan karena penyajian materi tentang hipertensi yang dijabarkan pada leaflet sudah cukup jelas. 
Sehingga lansia yang sebelumnya tidak pernah diberikan penyuluhan tentang hipertensi dapat membaca dan memahami isi leaflet dengan baik. Akan tetapi dari hasil penelitian terdapat beberapa lansia yang pengetahuannya masih tetap kurang sebelum maupun sudah diberikan leaflet, hal ini disebabkan karena lansia mengalami gangguan pengelihatan dan cenderung pelupa (pikun), sehingga lansia tidak dapat memahami isi leaflet dengan baik dan berdampak pada pengetahuan mereka.

\section{b. Efektifitas Leaflet Terhadap Pola Makan Lansia Penderita Hipertensi di Puskesmas Serasan Kabupaten Natuna}

Berdasarkan hasil penelitian diketahui bahwa $\mathrm{p}^{\text {value }}=0,038<0,05$. Hal ini menunjukan bahwa Ho ditolak yang artinya leaflet efektif dalam mempengaruhi pola makan lansia hipertensi dengan kata lain penyuluhan dengan menggunakan leaflet mempengaruhi pola makan pada lansia yang mengalami hipertensi di Puskesmas Serasan Kabupaten Natuna tahun 2015. Hal ini sejalan dengan penelitian penelitian Jayanti (2011), dengan judul efektivitas penyuluhan dan media leaflet terhadap pengetahuan dan sikap dalam mengatur pola makan balita gizi buruk Di Kecamatan Medan Denai dengan hasil uji chi square diperoleh nilai $\mathrm{p}=0,011<0,05$, artinya terdapat pengaruh antara penyuluhan dengan menggunakan leaflet terhadap perubahan pola makan lansia penderita Hipertensi.

Dari hasil penelitian diketahui terdapat perbedaan antara pola makan responden yang mendapatkan informasi dan yang tidak mendapatkan informasi melalui media leaflet tentang hipertensi, hal ini didukung oleh teori Wijaya (2010), yang menyatakan bahwa untuk mengatasi masalah pola makan pada lansia penderita hipertensi, dibutuhkan keterampilan dalam memberikan informasi agar penderita hipertensi dapat memahami tentang pola makan yang baik, seperti diet rendah garam dan banyak mengkonsumsi sayur atau buah-buahan.

Informasi merupakan sarana untuk mentransferkan ilmu pengetahuan terhadap seseorang, setelah mendapatkan pengetahuan maka dengan sendirinya akan terbentuk sikap dan tindakan yang menyatu menjadi sebuah perilaku. Untuk memberikan informasi dibutuhkan salah satu media yaitu leaflet. Kegunaan dan keunggulan leaflet adalah sederhana dan sangat murah, orang dapat menyesuaikan dan belajar mandiri, pengguna dapat melihat isinya pada saat santai, informasi dapat dibagikan dengan keluarga dan teman. Leaflet juga dapat memberikan detil (misalnya statistik) yang tidak mungkin bila disampaikan lisan (Adisusilo, 2010).

Berdasarkan hasil penelitian dan teori diatas, peneliti menyimpulkan bahwa leaflet efektif dalam mempengaruhi pola makan penderita hipertensi. Hal ini disebabkan karena sebelumnya responden sudah mengalami perubahan pengetahuan, dimana secara teoritis diketahui bahwa informasi yang disampaikan melalui leaflet dapat menstimulasi pengetahuan lansia penderita hipertensi. Selain itu dari data karakteristik responden diketahui banyak responden yang tidak bekerja, hal ini dapat mempengaruhi status ekonomi mereka, sehingga mereka sulit untuk mengkonsumsi banyak sayur maupun buah-buahan. Berdasarkan pengakuan responden dilapangan kepada peneliti sebagian dari mereka yang tidak mengalami perubahan pola makan menyatakan bahwa dukungan keluarga mereka kurang, karena keluarga dirumah mereka sering menyediakan masakan laut seperti udang, kepiting, kerang dan lainnya, dimana seafood memiliki kandungan garam yang cukup tinggi.

\section{KESIMPULAN DAN SARAN \\ Kesimpulan}

1. Terdapat perubahan pengetahuan lansia yang sudah diberikan leaflet, dan leaflet efektif terhadap pengetahuan penderita hipertensi di Puskesmas Serasan Kabupaten Natuna tahun 2015 dengan nilai $\mathrm{p}^{\text {value }}=0,000<0,05$.

2. Terdapat perubahan pola makan lansia yang sudah diberikan leaflet, dan leaflet efektif terhadap pola makan penderita hipertensi di Puskesmas Serasan Kabupaten Natuna tahun 2015 nilai $\mathrm{p}^{\text {value }}$ $=0,038<0,05$.

\section{Saran}

1. Bagi Puskesmas Serasan Kabupaten Natuna

Diharapkan kepada Puskesmas Serasan Kabupaten Natuna lebih meningkatkan pelayanan dibidang promosi kesehatan dengan cara memberikan penyuluhan secara berkelanjutan dan terjadwal (minimal 1 bulan sekali) dengan memperbanyak media seperti poster atau leaflet tentang penyakit hipertensi sebagai salah satu upaya untuk menurunkan angka kejadian hipertensI, kepada petugas 
kesehatan lebih melakukan sosialisasi kepada masyarakat khususnya lansia seperti melakukan peyuluhan tentang kesehatan lansia disetiap posyandu lansia agar lansia lebih tertarik dan menyadari akan pentingnya mendapatkan pelayanan kesehatan. Kepada kader lansia mendapatkan pelatihan tentang promosi kesehatan dalam kegiatan yang terkait dengan pelayanan kesehatan lansia dan kader juga dapat melakukan pendekatan atau sosialisasi dengan masyarakat setempat untuk meyakinkan masyarakat untuk meningkatkan pengetahuan dan dalam mengatur pola makan penderita hipertensi.

\section{Penelitian Lainnya}

Kepada penelitian selanjut diharapkan dapat meneliti jenis penelitian dan variabel yang berbeda

\section{UCAPAN TERIMA KASIH}

Kepada Instansi terkait, kepala Dinas Kesehatan Kabupaten Natuna, Kepala UPTD Puskesmas Serasan Kabupaten Natuna yang telah memberikan kesempatan kepada peneliti untuk melaksanakan penelitian. Serta kepada responden dan juga orang-orang yang banyak berperan hingga penelitian dapat diselesaikan.

\section{DAFTAR PUSTAKA}

Adisusilo, S. (2011). Pembelajaran NilaiKarakter. Jakarta : Rajawali Press

Adnani,H. (2014). Ilmu Kesehatan masyaarakat. Jakarta : Nuha Medika
Bustan, 2009. Epidemiologi Penyakit Tidak Menular. Jakarta : Rineka Cipta

Hastono \& Sabri, (2012). Statistik Kesehatan. Jakarta : Rajawali Press

Hidayat, A. (2007). Metode Penelitian Kebidanan dan Teknik Analisa Data. Jakarta : Salemba Medika

Hidayat, D. (2009). Ilmu Perilaku Manusia. Jakarta : Bina Pustaka

Haryono \& Setianingsih, (2011). Awas MusuhMusuh Anda Setelah Usia 40 Tahun. Jakarta : Publishing

Jayanti, (2011). Efektifitas Penyuluhan dan Media Leaflet Terhadap Pengetahuan dan Sikap Ibu Balita Gizi Buruk di Kecamatan Medan Demai www.http.jurnal.kesehatan.pdf.vol3421.

Khasanah, (2011). Pola Makan Khusus Pada Lansia www.http.jurnal.kesehatan.pdf.vol3421.

Kusumawardhani, (2009). Depresi Perimenopasue. Jakarta : FKUI

Notoatmodjo, S. (2010). Metode Penelitian Kesehatan. Jakarta : Rineka Cipta

Sulistyoningsih, (2012). Pola Makan Khusus Pada Lansia www.http.jurnal.kesehatan.pdf.vol3421

Purwandari, A. (2011). Ilmu Kesehatan Masyarakat Dalam Konteks Kebidanan. Jakarta : ECG 